\title{
Enzo PACE, Raccontare Dio. La religione come comunicazione
}

Bologna, Il Mulino, 2008, 354 p.

\section{Elena Zapponi}

\section{CpenEdition} Journals

Édition électronique

URL : http://journals.openedition.org/assr/21632

DOI : $10.4000 /$ assr.21632

ISSN : $1777-5825$

Éditeur

Éditions de l'EHESS

Édition imprimée

Date de publication : 31 décembre 2009

Pagination : $75-342$

ISBN : 978-2-7132-2218-4

ISSN : 0335-5985

Référence électronique

Elena Zapponi, «Enzo PACE, Raccontare Dio. La religione come comunicazione », Archives de sciences sociales des religions [En ligne], 148 | octobre-décembre 2009, document 148-99, mis en ligne le 27 janvier 2010, consulté le 21 septembre 2020. URL : http://journals.openedition.org/assr/21632 ; DOI : https://doi.org/10.4000/assr.21632

Ce document a été généré automatiquement le 21 septembre 2020

(c) Archives de sciences sociales des religions 


\section{Enzo PACE, Raccontare Dio. La religione come comunicazione}

Bologna, Il Mulino, 2008, 354 p.

\section{Elena Zapponi}

\section{RÉFÉRENCE}

Enzo PACE, Raccontare Dio. La religione come comunicazione, Bologna, Il Mulino, 2008, $354 \mathrm{p}$.

1 Ce livre, au titre évocateur, représente l'effort, bienvenu et innovateur dans le panorama de la sociologie de la religion italienne, de formuler une réflexion théorique sur la religion, son fonctionnement et son rôle sociétal.

2 Le propos de l'ouvrage, servi par un langage riche et élégant et une amplitude de références socio-anthropologiques ainsi qu'historiques et littéraires, est d'analyser le rapport entre religion et communication et, par conséquent, la relation qui s'établit entre l'individu, l'institution, le charisme, les symboles, les légitimations, les habitus mentaux.

3 La thèse sous-jacente à ces pages est la suivante: la religion représente un système sémantique, un code d'interprétation du monde dans lequel rien ne se crée, rien ne se détruit, les croyances circulant au fur et à mesure des siècles et créant une interdépendance des langages symboliques, une sorte de globalisation ante litteram ( $p$. 20). Selon Enzo Pace, les religions, telles des systèmes vivants, interagissent avec le milieu où elles s'enracinent et dont elles subissent les contrecoups; mais grâce au caractère entreprenant qui leur est consubstantiel, elles sont capables de s'y reproduire et de développer une fonction préservative de leur système.

4 Cette perspective soutient toute l'architecture du livre qui est articulée et argumentée en dialoguant constamment avec les grands auteurs de la théorie sociologique, à partir des pères fondateurs jusqu'aux auteurs plus récents. Nombreux sont les exemples 
concrets issus des grandes religions, des différents systèmes de croyance d'Orient ou d'Occident, du monde archaïque ou de la société-monde contemporaine observé dans sa tendance à la recomposition du croire et à la mobilité religieuse. Ces exemples, tels des pendants ponctuels, viennent éclaircir et compléter les affirmations théoriques de E.Pace et ce renvoi constant entre hypothèses théoriques et analyse des cas de terrain, entre théorie et praxis, détermine le caractère du livre et sa lecture agréable et claire.

Raccontare Dio est scandé en six temps qui correspondent aux différents chapitres dont les titres rendent compte de l'esprit de l'ouvrage et d'un propos de réflexion interdisciplinaire toujours à la lisière entre histoire des religions, sociologie comparative, philosophie et anthropologie cognitive: chap. I, La religion comme communication; chap. II, Religion et sens; chap. III, De la vertu de l'improvisation au système de croyance; chap. IV, L'esprit et l'ordre; chap. V, Les stratégies de communication dans les systèmes de croyance religieuse; chap. VI, Les religions entre éthique universelle et identification ethnique. Cet excursus rapide ne rend pas compte de la richesse de l'ouvrage, auquel on renvoie en souhaitant la prochaine parution d'une traduction française ou anglaise du texte. Il est cependant possible de souligner certains aspects qui paraissent particulièrement représentatifs de la réflexion développée par E.Pace.

6 En écartant soit le piège de la théorie de la sécularisation soit celui du retour du religieux, l'auteur prône une analyse centrée sur un regard de longue durée historique et insiste sur la capacité de la religion de «ressusciter» en fournissant des répertoires symboliques et des codes d'interprétations capables de mobiliser l'action sociale et politique. Il ne s'agit donc pas de disparition ni de retour mais d'un caractère syncrétiste propre à chaque religion et d'une loi de l'accumulation des différentes "couches de croyance» selon une échelle hiérarchique, rétablie à chaque tournant historique par les autorités qui gèrent et contrôlent la circulation des dites croyances au sein d'un système religieux spécifique.

7 Par cette approche, sont évitées les dichotomies tradition/modernité, primitif/évolué, simple/complexe, chères à l'histoire comparée des religions, la comparative religion née à la seconde moitié du XIX ${ }^{e}$ siècle, ainsi qu'une démarche de décomposition de la religion en différentes dimensions et éléments constitutifs ou toutes définitions essentialistes de la religion.

8 Selon la théorie des systèmes d'E. Pace, on est face à des «systèmes vivants» qui, à travers la communication, le pouvoir de «la parole pure de la religion», élaborent un code de réponse aux mutations de la société capable de transférer la «différenciation externe» de celle-ci en «différenciation interne».

9 Se déclarant proche de la méthode wébérienne de «l'analyse circulaire» des idéaltypes, E. Pace mise sur l'idée de mobilité et de la circulation de la religion: c'est vers «l'arte del comunicare» des systèmes religieux avec des contextes qui muent ainsi que vers leur " capacità autopoietica» ou autoréférentielle - dit E. Pace en citant Luhmann - et donc leur capacité de sauvegarder leur stock symbolique, rituel, mythologique, qu'il faut, selon ce sociologue, diriger le regard.

Dans cette perspective sont prises en considération différentes fonctions et manifestations de la religion, telles que le rapport entre la parole et le texte sacré, la performance liturgique, l'élaboration doctrinaire, l'oscillation typique des religions au sein des démocraties contemporaines entre prétention universaliste et identification ethnique. 
11 Mais le livre d'E. Pace n'est qu'une étude de l'appareil structurel des religions; il offre une analyse pointue de la «vertu de l'improvisation» exprimée par les personnalités religieuses charismatiques ou des cercles de sujets croyants (chap. III ); également, la quête de sens des acteurs croyants, qui établit une tension entre le patrimoine traditionnel codifié, sorte de stock de la mémoire et une recherche individuelle de mondes signifiants, au-delà des confins établis par l'institution, constitue un moment central de l'analyse, concrètement illustré.

Le parcours de La religione come comunicazione, décrit les religions comme des «systèmes experts», codes de complexité aptes à «interpréter» et définir l'ordre social et son intégration autant que sa remise en jeu selon un nouvel ordre et sa réinvention. Dans le livre, se trouve une métaphore qui revient à plusieurs reprises rappeler l'angle d'approche de l'auteur et l'accent qu'il met sur la notion de syncrétisme - notion assumée en tant qu'outil herméneutique décomplexé et épuré du pêché originel d'inauthenticité et conçue comme indispensable pour comprendre la mobilité du religieux - implicite à tout système de croyance religieuse: l'image d'une falaise, terrain capable d'absorber et de tolérer une stratification de symboles issus d'autres systèmes (pp.35, 305): «un système de croyance religieuse est souvent, pour reprendre une métaphore géologique, comme une falaise à plusieurs couches, qui ne sont pas superposées mécaniquement mais plutôt tenues ensemble de telle façon qu'elles apparaissent plus ou moins harmoniquement mises en place ou hiérarchiquement ordonnées et disciplinées» (p.323). 